\title{
NOVAS TECNOLOGIAS: RECURSOS PARA UMA ESCRITA COGNITIVA
}

\author{
Andrea Barbosa Gomes Pereira ${ }^{1}$
}

\section{RESUMO}

Este artigo objetiva discorrer de forma breve acerca das contribuições das novas tecnologias para uma produção textual cognitiva a partir das ferramentas e recursos tecnológicos. Sabe-se que a escrita é um elemento fundamental na vida cotidiana e seu ensinamento, principalmente em escolas públicas, constitui um grande desafio aos educadores. Em decorrência, assinalam-se questões sobre do papel dos educadores diante das demandas socioculturais contemporâneas, apontam-se alguns levantamentos com vistas a enfrentar o desafio de pensar uma sala de aula que alcance outros espaços e tempos. Nesse paradigma, o questionamento levantado foi se práticas pedagógicas desenvolvidas atualmente preparam os alunos para uma escrita cognitiva. A metodologia utilizada foi a pesquisa bibliográfica num paradigma qualitativo. Os resultados apontam para implicações positivas quanto à integração das TDIC nas práticas pedagógicas para a produção textual. Os teóricos aqui reportados são: Guaresi; Borba, Pereira e Santos; Carnin, Graça e Pereira; Almeida e Valente; Silva; Santaella; Rangel e Rojo; Moura e Rojo.

Palavras-chave: Escrita. Tecnologias digitais de informação e comunicação (TDIC). Educador.

\footnotetext{
${ }^{1}$ Graduada em Letras e em Pedagogia, especialista em Gestão Pública Municipal pela Universidade Federal do Estado do Rio de Janeiro - UNIRIO e especialista em Psicopedagogia Institucional pela Faculdade Paulista de Serviço Social de São Caetano do Sul - FAPSS. E-mail: andreabgpereira@gmail.com.
} 


\section{ABSTRACT}

This article aims to briefly discuss the contributions of new technologies to a cognitive textual production based on technological tools and resources. It is known that writing is a fundamental element in everyday life and its teaching, mainly in public schools, constitutes a great challenge for educators. As a result, questions are raised about the role of educators above the contemporary socio-cultural demands, some surveys are pointed out in order to face the challenge of thinking about a classroom that reaches other spaces and times. In this paradigm, the question raised was whether pedagogical practices currently developed prepare students for cognitive writing. The methodology used was bibliographic research with a qualitative paradigm. The results point to positive implications regarding the integration of TDIC in pedagogical practices for textual production. The theorists reported here are: Guaresi; Borba, Pereira and Santos; Carnin, Graça and Pereira; Almeida and Valente; Silva; Santaella; Rangel and Rojo; Moura and Rojo.

Keywords: Writing. Digital information and communication technologies (TDIC). Educator.

\section{INTRODUÇÃO}

A escrita faz parte do nosso cotidiano como uma prática corriqueira. No contexto educacional, refere-se ao processo cognitivo que envolve dentre outros elementos, a codificação, decodificação, percepção, memorização, atribuição de significado, tornando-se uma atividade muito complexa.

Como educadores não podemos negar o envolvimento dos alunos com as novas tecnologias digitais de informação e comunicação - TDIC. O debate que aqui se propõe busca uma reflexão sobre as contribuições das novas tecnologias digitais para a escrita e seu impacto sobre a construção conhecimento além dos muros escolares.

Vivemos em um mundo multiletrado, no qual a escrita assume várias facetas o que se configura como um desafio para muitos educadores. No entanto, muitos 
estudos mostram que a integração das TDIC nas práticas pedagógicas pode contribuir para um aprendizado mais significativo para o alunado.

O objetivo deste estudo é investigar as principais contribuições das novas tecnologias digitais de informação e comunicação para a produção cognitiva de textos. A importância desse estudo se justifica em apontar o impacto positivo da integração das TDIC no processo educativo.

O problema que se levanta aqui é se as práticas pedagógicas desenvolvidas pela escola atualmente contribuem para uma escrita cognitiva. As hipóteses aqui levantadas são que: 1- as novas tecnologias digitais são utilizadas como recursos pedagógicos de aprendizagem; 2- os educadores estão motivados a integrar as tecnologias digitais em suas práticas pedagógicas.

Para responder a essas indagações, a metodologia aqui utilizada foi a pesquisa bibliográfica com enfoque qualitativo, tendo como base os estudos e pesquisas de Creswell (2014) e Severino (2007). Serão utilizadas como fontes de pesquisa bibliográfica artigos científicos e livros.

Observamos que existem muitos artigos que discutem os processos cognitivos envolvidos na aprendizagem da leitura e uma quantidade menor sobre a escrita. Assim, a possibilidade de discutir sobre a escrita é de fundamental importância para este estudo.

Para fundamentação teórica e a fim de esclarecer a problemática levantada privilegiamos os estudos de GUARESI (2014), BORBA, PEREIRA e SANTOS (2014), CARNIN, GRAÇA e PEREIRA (2014), ALMEIDA e VALENTE (2012), SILVA (2016), RANGEL e ROJO (2010), SANTAELLA (2013) e ROJO (2012).

Nesse sentido, observamos o artigo de Guaresi (2014) que objetivou destacar algumas descobertas da neurociência e suas implicações para a educação, mais especificamente as intervenções pedagógicas que podem ser mobilizadas a favor de um melhor aprendizado.

Também consideramos o estudo de Borba, Pereira e Santos (2014) que relata alguns processos cognitivos envolvidos na aprendizagem da leitura e da escrita e a complexidade desses processos.

Carnin, Graça e Pereira (2014) apresentam considerações sobre alguns modelos de formação de professores, no Brasil e em Portugal, para o ensino da escrita. 
O estudo de Santaella (2013) discorre sobre os modelos de educação online como novos paradigmas de aprendizagem e o papel do educador mediador no processo de ensino e aprendizagem.

Almeida e Valente (2012) fazem uma abordagem acerca da integração das TDIC ao currículo, do impacto causado na sociedade pelas tecnologias e das formas de produção de textos advindas da cultura digital.

Silva (2016) apresenta alguns pressupostos metodológicos da Pedagogia dos Multiletramentos aplicados na educação brasileira.

A obra de Rojo e Moura (2012) é baseada na Pedagogia dos Multiletramentos e destaca a necessidade de incluir propostas de multiletramentos, que considerem a diversidade cultural e de linguagem existentes na escola, por meio da utilização das TDIC.

Já a coletânea de Rangel e Rojo (2010) traz uma importante contribuição para o professor de Língua Portuguesa. Faz uma abordagem acerca de alguns dos desafios enfrentados pelos professores na contemporaneidade sob diversos aspectos.

\section{PROCESSOS COGNITIVOS DA ESCRITA}

A cognição humana vem sendo bastante estudada em diversos campos da ciência, o que possibilitou um conhecimento mais aprofundado do funcionamento cerebral, consequentemente, dos processos cognitivos que abrangem 0 desenvolvimento da produção textual. Esses processos dizem respeito à maneira como a informação é mobilizada a favor da aprendizagem.

O cérebro é o grande administrador do nosso corpo; todo o organismo humano é gerenciado pelo sistema nervosos central. Os estímulos provindos dos órgãos dos sentidos são percebidos e processados pelo cérebro promovendo alguma alteração na força das sinapses, fenômenos eletroquímicos no contato dos filamentos neuronais. (GUARESI, 2014, p. 55)

A produção textual escrita é um processo complexo que envolve a mobilização de outras competências e habilidades como codificação, decodificação, memorização, percepção, atribuição de sentido etc. e que somada a importância e potencialidade da adoção das TDIC em sala de aula pode levar os 
alunos a uma aprendizagem significativa que os façam refletir de maneira crítica sobre sua realidade.

Produzir um texto é uma atividade bastante complexa e pressupõe um sujeito não apenas atento às exigências, às necessidades e aos propósitos requeridos por seu contexto sócio-histórico e cultural, mas também capaz de realizar diversas ações e projeções de natureza textual, discursiva e cognitiva, antes e no decorrer da elaboração textual. (MARCUSCHI apud RANGEL e ROJO, 2010, p.65).

A produção textual envolve muitos aspectos cognitivos, dentre os quais a leitura, a experiência com modelos de gêneros textuais e a memorização são muito importantes, alguns estudos apresentam a ideia de que a escrita é o produto final de outras competências (CARNIN, GRAÇA, PEREIRA, 2014).

Para Borba, Pereira, Santos (2014, p.23), "cabe à escola oferecer experiências de qualidade para o desenvolvimento tanto da leitura quanto da escritura". Nesse sentido, oportunizar atividades e práticas de escrita que permitam ao aluno produzir textos nos quais possa expor sua cultura em um ambiente que habita com certa facilidade pode representar um aprendizado mais significativo.

O novo cenário aponta para novas formas de comunicação, para tanto é preciso rever antigas práticas pedagógicas e promover eventos de letramento capazes de desenvolver nos alunos competências e habilidades de leitura e de escrita que a contemporaneidade exige. Nesse sentido, ROJO (2010, p. 11) diz que os letramentos múltiplos, em suas implicações, escolares e pessoais, devem ser, portanto, a matéria-prima do ensino-aprendizagem de Língua Portuguesa.

Os textos escritos agora são projetados de maneira altamente visual, e os significados e os sentidos são realizados tanto pela multimodalidade como pelas palavras e frases do letramento tradicional, o que significa que o ensino das formas tradicionais de letramento alfabético precisa ser suplementado pela aprendizagem dos designs multimodais dos textos. (SILVA, 2016, p.17)

Em consequência dessa situação, percebe-se que a produção de diferentes textos é uma atividade imprescindível para a formação de um aluno crítico e com capacidade para escrever textos com finalidades diferenciadas para os diversos contextos contemporâneos. 


\subsection{O IMPACTO DAS NOVAS TECNOLOGIAS NA EDUCAÇÃO}

O mundo está cada vez mais cercado das TDIC, e utilizar essas tecnologias no contexto pedagógico é uma forma de aproximar e motivar os alunos, pois a partir da integração das TDIC é possível uma reconfiguração do fazer pedagógico permitindo uma expansão curricular para além das fronteiras de espaço e de tempo. Pois, segundo ROJO (2012, p. 37), "as tecnologias digitais estão introduzindo novos modos de comunicação, como a criação e o uso de imagens, de som, de animação e a combinação dessas modalidades".

Observa-se que a midiatização tecnológica tornou mais viável e tem influenciado a escola e as práticas pedagógicas de muitos educadores. ALMEIDA e VALENTE (2012, p.60) dizem que "as TDIC propiciam a reconfiguração da prática pedagógica, a abertura e plasticidade do currículo e o exercício da coautoria de professores e alunos", assim, o conhecimento pode ser produzido em qualquer lugar.

Muitos estudos demonstram que as TDIC pouco foram integradas ao ambiente escolar como suporte pedagógico, sua adoção se deu mais com relação aos equipamentos tecnológicos que foram incorporados ao ambiente escolar como material de apoio, muitos professores também utilizam as tecnologias de forma pessoal, no entanto, a integração das tecnologias digitais como práticas de aprendizagem ainda acontece de maneira discreta, principalmente em escolas públicas.

As TDIC impuseram uma mudança na linguagem, misturando a linguagem escrita com outras formas de linguagem, surgindo, assim, a multimodalidade. Devido à multimodalidade e hipertextualidade trazida pelas TDIC é que se faz necessário também um upgrade nas competências de leitura e de escrita dos alunos. Nesse sentido, RANGEL e ROJO (2010, p. 27,28) diz que

Novas tecnologias digitais da informação e da comunicação tomaram conta de nossas vidas, não somente pelos computadores, mas também pelos celulares, televisores etc., mantendo-nos permanente e globalmente conectados, num mundo de informação e comunicação rápidos que alteram as barreiras de espaço e de 
tempo. Mais que isso, essas tecnologias tornaram-se as ferramentas e as formas principais do trabalho em nossas sociedades urbanas contemporâneas.

Dessa forma, pode-se dizer que as TDIC estão ressignificando as práticas de ensino e de aprendizagem por meio de atividades em ambientes virtuais, e uma transformação no fazer pedagógico é fundamental para que o aluno deixe de ser um espectador para ocupar a posição de protagonista no processo educativo.

\subsection{O PAPEL DO EDUCADOR NA INTEGRAÇÃO DAS}

\section{TDIC}

A integração das TDIC no processo educativo é cada vez mais exigida nos novos contextos sociais, por isso, a educação precisa ser pensada para alcançar as necessidades e expectativas do aluno contemporâneo. Nesse contexto, o papel do educador torna-se imprescindível para preparar o aluno para as múltiplas práticas que o mundo moderno exige.

A presença das tecnologias digitais em nossa cultura contemporânea cria novas possibilidades de expressão e comunicação. Cada vez mais, elas fazem parte do nosso cotidiano e, assim como a tecnologia da escrita, também devem ser adquiridas. (ROJO, 2012, P.37)

Nesse cenário conectado, cabe ao educador trabalhar com diferentes textos em gêneros variados e mídias diversas que abordem distintas culturas e linguagens para que o aluno se torne mais crítico, reflexivo, consciente e responsável por suas escolhas.

Dessa forma, a grande oportunidade de acesso às informações não é suficiente para desenvolver nos alunos uma formação plena, torna-se, então, necessário uma ação docente para perceber as necessidades e interesses dos alunos e utilizar uma prática pedagógica com contextos significativos capaz de desenvolver nos alunos habilidades e competências para uma análise e reflexão consciente e crítica sobre o mundo. 
Para trabalhar nessa perspectiva, o professor deve engajar as crianças no processo e traçar estratégias que as levem do conhecimento prévio à criação. Durante essa criação, será possível abordar o currículo escolar, o sistema de escrita, ampliar o repertório e transitar pelas diversas modalidades e coleções culturais. (ROJO, 2012, P.38)

É preciso ressaltar que a aprendizagem ubíqua não substitui os processos formais de ensino, tão pouco a presença do professor. A aprendizagem ubíqua vem completar o processo presencial de ensino e de aprendizagem. Nesse sentido, pode-se dizer que o papel do educador se modificou, exigindo grande capacidade de adaptação e criatividade para atender às expectativas de aprendizagem dos alunos, para SANTAELLA (2013, p.14),

Novas modalidades de diálogo estão emergindo, para as quais o professor deve estar preparado na medida em que tiver a segurança serena em relação ao fato de que ficou no passado a era na qual costumava ser o detentor altissonante da transmissão e da transferência de conhecimento.

A exigência social posta é de um educador apto a mediar o processo de educação também em um ambiente virtual, dando aos alunos as ferramentas necessárias para que consigam, por meio de processos cognitivos, perceberem a confiabilidade das informações que circulam na internet, selecionarem o que é confiável, confrontarem uma informação com outra, entenderem os contextos nos quais a informação foi produzida, dentre outros.

\section{CONCLUSÃO}

Vimos que a escrita é um elemento crucial do processo educativo e que pode influenciar de modo determinante o desenvolvimento do processo de ensino e de aprendizagem, afetando significativamente os alunos, caracterizando-se como uma prática primordial na vida das pessoas.

Sabemos que as TDIC estão ressignificando a educação por meio de novas oportunidades de ensino e aprendizagem em ambiente virtual, cabe ressaltar que os desafios para integração das TDIC são muitos, porém os resultados obtidos 
serão positivos à medida que os alunos se sentirão motivados a aprender a escrever.

Observamos, então, que as TDIC podem auxiliar o educador a atender às necessidades individuais dos alunos e permitir que eles se tornem protagonistas no processo de ensino e aprendizagem, além de contribuir significativamente para o processo educativo, pois oferecem um aprendizado ubíquo.

Salienta-se, ainda, que esses conhecimentos possibilitam aos educadores romperem com velhas práticas pedagógicas e permitem uma melhor compreensão da cultura dos alunos, como também das suas dificuldades linguísticas, possibilitando, dessa forma, um melhor ajuste da prática pedagógica às necessidades de aprendizagem dos alunos.

Para tanto, incentivar os alunos a produzirem textos utilizando as TDIC é trabalhar para desenvolver a potencialidade de cada aluno, a produção escrita multissemiótica e contribuir para transformar os alunos em escritores competentes e protagonistas no processo de ensino e aprendizagem.

Neste artigo, não almejamos analisar de maneira exaustiva todas as possibilidades de contribuição das TDIC no processo de produção textual, mas, sim, destacar algumas contribuições como recursos para auxiliar no processo de escrita. 


\section{REFERÊNCIAS}

ALBUQUERQUE, Eliana Borges Correia de. Conceituando alfabetização e letramento. In: Santos, Carmi Ferraz \& Mendonça, Márcia (org.). Alfabetização e letramento: conceitos e relações. 1.ed., 1.reimp. - Belo Horizonte: Autêntica, 2007.

ALMEIDA, M. E. B.; VALENTE, J. A. Integração currículo e tecnologias e a produção de narrativas digitais. Currículo Sem Fronteiras, 12(3), 57-82. Disponível em: http://www.curriculosemfronteiras.org/vol12iss3articles/almeida-valente.pdf. Acesso em: 31 de mar. de 2020.

BORBA, V. C. M.; PEREIRA, M. R. A.; SANTOS, A. P. Leitura e escritura: processos cognitivos, aprendizagem e formação de professores. Disponível em: http://www.ufrgs.br/inov/docs/educacaoedirhumnumaperspecintercult. Acesso em: 23 de mar. de 2020.

CARNIN, A.,GRAÇA, L., PEREIRA, L.A. Modelos de formação para o ensino da escrita em Portugal e no Brasil. Disponível em: http://www.ufrgs.br/inov/docs/ educacaoedirhumnumaperspecintercult. Acesso em: 30 de mar. de 2020.

CRESWELL, J. W. Investihação Qualitativa e Projeto de Pesquisa: escolhendo entre cinco abordagens. 3ed. Porto Alegre: Penso, 2014.

DIAS, M.G.B.B., ROAZZI, A., SANTANA, S.M. Paradigmas do desenvolvimento cognitivo: uma breve retrospectiva. Disponível em: http://www.scielo.br/scielo. php?script=sci_arttext\&pid=S1413-294X2006000100009. Acesso em: $1^{\circ}$ de abr. de 2020.

GUARESI, Ronei. Repercussões de descobertas neurocientíficas ao ensino da escrita. Disponível em: https://www.revistas.uneb.br/index.php/faeeba/ article/viewFile/823/581. Acesso em: 29 de mar. de 2020. 
LEO, Fraiman. Como ensinar bem a criança e adolescentes de hoje: teoria e prática.1 $1^{\underline{a}}$ ed. São Paulo: Editora Esfera, 2013.

MOURA, Eduardo e ROJO, Roxane Helena Rodrigues (organizadores). Multiletramentos na escola. São Paulo: Parábola Editorial, 2012.

RANGEL, Egon de Oliveira (coord) e ROJO, Roxane Helena Rodrigues (coord). Língua Portuguesa: ensino fundamental. Brasília: Ministério da Educação, Secfretaria de Educação Básica: 2010.

SANTAELLA, Lucia. A EAD e o potencial das tecnologias: concepções, modelos e novos paradigmas. Disponível em: http://institutologos.org/cursos/pluginfile. php/10914/mod_resource/content/1/Artigo_Santaella.pdf. Acesso em: 02 de abr. de 2020.

SEVERINO, Antônio Joaquim. Metodologia do trabalho científico. $23^{\mathrm{a}}$ ed. rev. E atual. São Paulo: Cortez, 2007.

SILVA, T. R. B. C. Pedagogia dos Multiletramentos: principais proposições metodológicas e pesquisas no âmbito nacional. Disponível em: http://institutologos.org/cursos/pluginfile.php/8255/mod_resource/content/2/Artigo \%20Multiletramentos.pdf. Acesso em: 30 de mar. de 2020. 